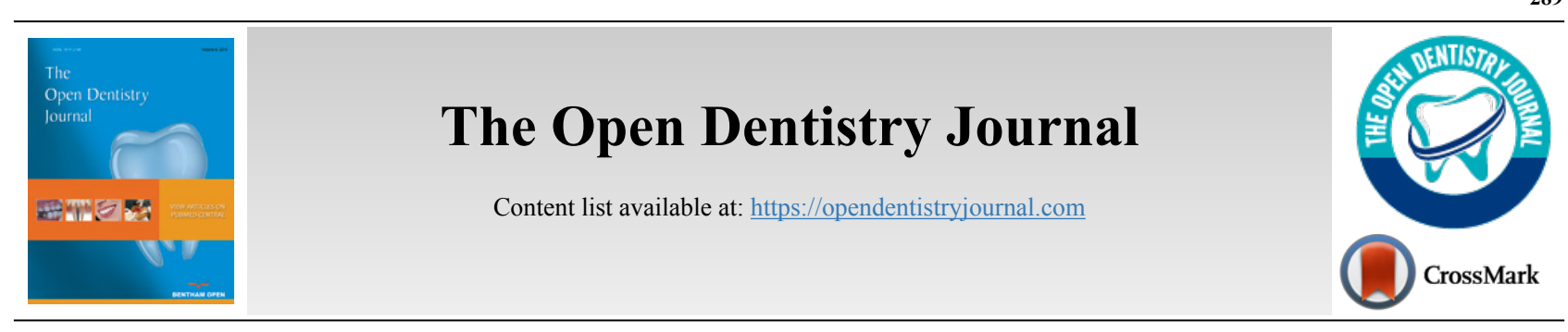

$\mathbf{E}^{\prime}, 725, \$ /$

\title{
Oral and Maxillofacial Surgery in Front of Covid-19
}

\author{
Luiza Z Reolon ${ }^{2}$, Rogério Belle de Oliveira ${ }^{2}$ and Orion L. H. Junior ${ }^{1, *}$ \\ ${ }^{\prime}$ Department of Oral and Maxillofacial Surgery, Pontificia Universidade Católica do Rio Grande do Sul, Porto Alegre, Brazil \\ ${ }^{2}$ Department of Oral and Maxillofacial Surgery, Hospital Sao Lucas, Porto Alegre, Brazil
}

The pandemic of the new coronavirus or SARS-CoV-2 abruptly changed the lives of global population and unleashed an emergency situation in international public health, causing the disease named COVID-19. A new and challenging disease, in constant transformation as for the understanding of the health-disease process, bringing uncertainties towards the availability of vital resources and consequent concern with general well-being. The Oral and Maxillofacial Surgery specialty, as other areas of dentistry, suffered significant impact in safe practice of its procedures due to direct professional contact with oral and nasal mucous, that are considered areas of high risk of infection in virtue of viral charge and great possibility of exposure to biological materials proportionated by the generation of aerosol during procedures $[1,2]$.

Biosafety is the condition achieved by a set of actions intended to prevent (cross infections), control (radiation and use of materials), reduce (biological accidents) or eliminate (microorganisms) inherent risks to the activities that might compromise human (professionals, patients, collaborators), animal and environment health, rules even more in current clinical practices. Next to the goal of avoiding viral propagation, measures have been taken, among them social distancing, optimization and allocation of limited resources, such as Personal Protective Equipment (PPE) and the suspension of elective surgeries [3].

In times of outbreak of COVID-19, dental procedures in ambulatory or hospital environment have been restricted to emergency cases (risk of death) like bleeding, cellulite or diffuse bacterial infections, with intra or extraoral edema and fracture of the facial bones, possibly compromising the patient's airway; and the urgency care (priority, but do not characterize risk of death), such as acute odontogenic pain, pericoronaritis, alveolites, periodontal or dental abscesses, den-

\footnotetext{
* Address correspondence to this author at the Department of Oral and Maxillofacial Surgery, Pontifícia Universidade Católica do Rio Grande do Sul, Avenida Ipiranga, 6681, Building 6, 90619-900 - Porto Alegre, Brazil; Tel.: +55 51 999679116; E-mail: olhj@hotmail.com
}

tal fracture with painful symptoms or trauma of oral soft tissues, need of dental treatment prior to a critical medical procedure, biopsies, treatment of tissue necrosis, mucositis and dental trauma with avulsion or dislocation [4].

Soft facial tissue injuries and/or trauma involving facial bones display indication of debridement, washing the wound with saline and drying with surgical aspirator or gauze. If there is a need for sutures, selection of absorbable string and then defining the patient's hospitalization or hospital discharge is essential. The treatments related to facial bone fracture follow specific recommendations based on the anatomical region affected.

In general, opt for closed reduction and when indicated elect self-drilling screws, the cases that lack fixation and consequent drilling, adhere to minimal irrigation. The monopolar electrocautery is recommended for the incisions and bipolar for hemostasis, both at low power, preferring extraoral to intraoral approach [5]. This is a unique moment in which surgeons should consider alternative treatments and practice conservation for greater functionality of the health system. French [6] have instructed home isolation of the patient for fourteen days after hospital discharge. It is worth emphasizing that the urgency of a procedure in front of the present momentary health situation must be decision based on critical clinical judgment, and to be defined case by case.

Given the unfeasibility of postponing a procedure, a series of protective measures should be followed in order to prevent cross contaminations. The environmental service must provide inputs (water, liquid soap, paper towel, bottles with $70 \%$ alcohol preparation) for hand hygiene of the patients and eventual companions. The space needs a cleaning reinforcement before and after service, mainly those with greater contact with $70 \%$ alcohol solutions and suction equipment with chlorine-based agents. Professionals and collaborators need to wash their hands with water and liquid soap or $70 \%$ alcoholic solution before and after contact with the patient or infected surfaces. The meticulous protection actions, such as vestment with Personal Protective Equipment 
(PPE) - bonnet, protection glasses, N95/PFF2 masks or equivalents, as a facial protector, minimum weight waterproof apron of $50 \mathrm{~g} / \mathrm{m}^{2}$ and procedure gloves to all members of the team. It should be noted that one of the main routes of contamination of the health professional takes place at the time of taking off the vestment, so the importance of standardization should be considered to avoid any risk [7]. The operating rooms, considered ideal models for the procedures in the face of the pandemic, are the ones that have negative pressure and high efficiency of the particulate air filter, however, it is the reality of few health services. So parameters need to be imposed by limitation of professionals involved in surgery, restriction of staff and material turnover in the transoperative period. Considering that the contamination risk would be increased by the aerosols of engines, drills, piezoelectric, fluid leak from intubation tubes, to prevent viral dispersion to the aspiration of saliva and other potentially contaminated secretions, needs to be continuous and high power [6].

Although no topical therapy has been studied specifically to amortize viral charge and aerosolization potential of SARSCoV-2 during mucosal surgery of the upper airways, the solutions of povidone-iodine, chlorhexidine and hydrogen peroxide have been evaluated in order to reduce the risks of transmission. The $75 \%$ concentration of povidone-iodine diluted in saline solution 1:3 demonstrated efficacy against viral activity in other types of coronavirus. It is a relatively safe solution for use in the upper airways in a short application time (one minute) and can restrict threats of SARS-CoV-2 during surgery of the mucous membranes of the upper airways. The contraindication to topical iodine is related to allergic patients/ anaphylaxis, thyroid pathologies, contact dermatitis, pregnant women and people on active radioiodine therapy. As for the chlorhexidine, it has antibacterial action and is believed not to be effective for this type of virus [8]. The 0,5 to $1 \%$ hydrogen peroxide can also be used as a virus inhibitor prior to procedures, mainly for mouthwash [9].

Amid the dynamic environment of the pandemic, it is up to health professionals to seek constant updates, as the guidelines and parameters are changing continuously. Meanwhile, ethical precepts state appropriately that during an unprecedented event, it is necessary to maintain adherence to the principals of beneficence, justice, faithfulness, veracity and respect for people.

\section{REFERENCES}

[1] Zou L, Ruan F, Huang M, et al. SARS-CoV-2 Viral Load in Upper Respiratory Specimens of Infected Patients. N Engl J Med 2020; 382(12): 1177-9.

[http://dx.doi.org/10.1056/NEJMc2001737] [PMID: 32074444]

[2] Susarla SM, Parmar S, Fernandes R. COVID-19 and the craniomaxillofacial surgical community. Craniomaxillofac Trauma Reconstr 2020; 1http://journals.sagepub.com/ doi/ $10.1177 / 1943387520921325$

[3] Diaz A, Sarac BA, Schoenbrunner AR, Janis JE, Pawlik TM. Elective surgery in the time of COVID-19. Am J Surg [Internet] 2020; (xxxx): 1-3. Available from: https://linkinghub.elsevier.com/ retrieve/pii/ S000296102030218X

[4] American Dental Association (ADA). Constitutes a Dental Emergency? 2020; $1 . \quad$ Available from: https://success.ada.org/ /media/CPS/Files/ Open Files/ ADA_COVID19_Dental_Emergency_DDS.pdf?utm_source=adaorg\& utm medium $=$ covid-resourceslp\&utm content $=$ cv-pm-emergdef\&utm campaign $=$ covid19\& ga $=2.158719422 .527261862 .1584796$ 909-1982106663.1584563184

[5] AO CMF International Task Force. AO CMF International Task Force Recommendations on Best Practices for Maxillofacial Procedures during COVID-19 Pandemic. 1-6. Available from: http:/go.aocmf.aofoundation.org/e/ \%0A700333/ d-19-task-forceguidelines-

pdf/g1mvl/61093701?\%0Ah1/4asHHpTEGtRgEQODbr_GvMPg8Fon X6ecjoPQ8q\%0AHKM8ZA

[6] French T, Surgery M, Sfscmfco OS. French Society of Stomatology, Maxillo-Facial Surgery and Oral Surgery (SFSCMFCO). Practitioners specialized in oral health and coronavirus disease 2019: Professional guidelines from the French society of stomatology, maxillofacial surgery and oral surgery, to form a common front against the infectious risk. J Stomatol Oral Maxillofac Surg 2020; 121(2): 155-8. [http://dx.doi.org/10.1016/j.jormas.2020.03.011] [PMID: 32307085]

[7] Servi ESP, Sa OSDE, Preven MDE, Que C, Ser D, Durante A, et al. Orientacoes para servicos de saude: Medidas de prevencao e controle que devem ser adotadas. 2020; 53 Available from: http://portal.anvisa.gov.br/documents/ 33852/ 271858/Nota+T

[8] Parhar HS, Tasche K, Brody RM, Weinstein GS, O'Malley BW, Shanti RM, et al. Topical preparations to reduce SARS $\square \mathrm{CoV} \square 2$ aerosolization in head and neck mucosal surgery. Head Neck [Internet] 2020 Apr; 25(April): hed.26200. Available from: http://www.ncbi.nlm.nih.gov/pubmed/32333619

[9] Zhang W, Jiang X. Measures and suggestions for the prevention and control of the novel coronavirus in dental institutions. Front Oral Maxillofac Med 2020; 2: 1-4.

[http://dx.doi.org/10.21037/fomm.2020.02.01] 